\title{
Understanding the Timing of Hydrocarbon Generation and Oil-Source Correlation Using Rhenium-Osmium (Re-Os) Isotopes
}

\section{Sarah Porter, Chemostrat Ltd}

Uncertainties regarding the timing of oil generation and the source of the generated oil are common exploration problems. Understanding the chemical composition of petroleum source rocks and their associated oils provides critical information regarding the temporal and spatial controls on the formation of hydrocarbon deposits. Further, direct radiometric dating of hydrocarbons yields the timing of oil generation and so provides a robust temporal constraint on the timing of oil formation and migration within the petroleum system. Determining the age of the generated oil also has the potential to enable identification of the source rock, thus providing significant potential for oil-to-source correlation studies. Understanding how and when oil moves from its source rock to the reservoir has the potential to provide insight into oil migration pathways, basin, reservoir and trap structure, and also the ability to highlight possible new oils. As such, oil-to-source fingerprinting is an exceptionally valuable tool in petroleum exploration.

Rhenium-osmium geochronology exploits the decay of ${ }^{187} \operatorname{Re}$ to ${ }^{187}$ Os. The enrichment of these elements in shales, black shales and the asphaltene fraction of whole oil makes them ideal parameters in the study of heavy oils. Further, the Re-Os geochronometer can be used to directly date hydrocarbon deposits, thus constraining the timing of oil generation.

Oil to source rock correlation relies on identifying and utilising genetic parameters that are internally consistent between an oil and its source rock. These parameters should be relatively insensitive to the effects of biodegradation, variations in thermal maturity, and solubilisation and geochromatography during migration; factors which can play a prominent role in heavy oil dominated petroleum systems. Using case studies from the Middle East and the oil sands of the Western Canada Sedimentary Basin, we demonstrate that the osmium isotopic composition of an oil is inherited from its source rock, thus making it an ideal candidate for oil-source correlation work. Trace element geochemistry has also been utilised to identify and characterise tar mat signatures, thus further enabling and enhancing correlation work. In addition, studies have demonstrated that the Re-Os isotope system is exceptionally robust, and not affected by the processes of thermal maturation, oil migration or biodegradation, making it an ideal candidate for application to heavy oil systems. 